TI 2011-163/3

Tinbergen Institute Discussion Paper

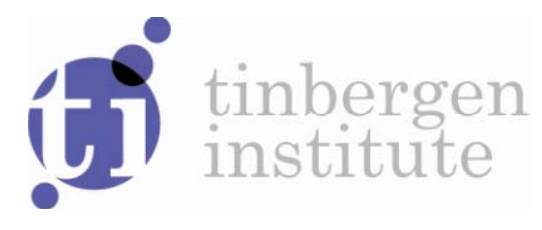

\title{
Labor Market Dynamics and Technology Adoption: Theory and Empirical Evidence
}

Stilianos Alexiadisa

Konstantinos Eleftherioub

Peter Nijkampc

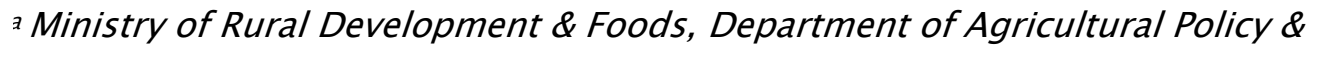
Documentation, Greece;

b University of Piraeus, Department of Economics, Greece;

c Faculty of Economics and Business Administration, VU University Amsterdam, Netherlands. 
Tinbergen Institute is the graduate school and research institute in economics of Erasmus University Rotterdam, the University of Amsterdam and VU University Amsterdam.

More TI discussion papers can be downloaded at http://www.tinbergen.nl

Tinbergen Institute has two locations:

Tinbergen Institute Amsterdam

Gustav Mahlerplein 117

1082 MS Amsterdam

The Netherlands

Tel.: +31(0)205251600

Tinbergen Institute Rotterdam

Burg. Oudlaan 50

3062 PA Rotterdam

The Netherlands

Tel.: +31(0)10 4088900

Fax: $+31(0) 104089031$

Duisenberg school of finance is a collaboration of the Dutch financial sector and universities, with the ambition to support innovative research and offer top quality academic education in core areas of finance.

DSF research papers can be downloaded at: http://www.dsf.nl/

Duisenberg school of finance

Gustav Mahlerplein 117

1082 MS Amsterdam

The Netherlands

Tel.: +31(0)20 5258579 


\title{
Labor Market Dynamics and Technology Adoption: Theory and Empirical Evidence*
}

\author{
Stilianos Alexiadis ${ }^{\mathrm{a}}$

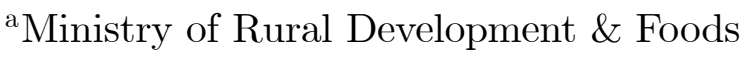 \\ Department of Agricultural Policy \& Documentation \\ Greece
}

\author{
Konstantinos Eleftheriou ${ }^{\mathrm{b}}$ \\ ${ }^{\mathrm{b}}$ University of Piraeus \\ Department of Economics \\ Greece
}

\author{
Peter Nijkamp ${ }^{c}$ \\ ${ }^{c}$ VU University Amsterdam \\ Department of Spatial Economics \\ The Netherlands
}

\begin{abstract}
Using 'search' theory, technology adoption is conceived of as a critical factor in the aftermath of a technological shock, which increases employment in the leading sectors and total output in the economy. These implications are further investigated in the present paper, both formally and empirically. Our attempt to investigate this hypothesis empirically across ten OECD countries, appears to provide various affirmative results.
\end{abstract}

Key Words: Search Theory, Technological Shock, Technology Adoption

JEL Classification: J62, J64

\section{Introduction}

There is little doubt that technological advances constitute one of the most important channels that enables an economy to follow a novel evolutionary path. This, indeed, is almost an article of faith for the various models of economic growth, especially those developed in the strand of endogenous growth theory. ${ }^{1}$ At the heart of this theory there is a sector that deliberately produces technological

\footnotetext{
${ }^{*}$ Corresponding author: Peter Nijkamp, Department of Spatial Economics, VU University, De Boelelaan 1105, 1081 HV Amsterdam, The Netherlands. E-mail: p.nijkamp@vu.nl. The findings, interpretations and conclusions are entirely those of the authors and do not necessarily represent the official position, policies or views of the Ministry of Rural Development and Foods and/or the Greek Government.

${ }^{1}$ Romer (1990) developed a most instructive model in this area. Thoughtful surveys of this field include Pack (1994) and Fine (2000).
} 
innovations. ${ }^{2}$ This sector combines human capital with the existing stock of knowledge to produce new knowledge, which enhances productivity, and is available to other sectors of the economy at virtually zero marginal cost (Stern, 1991). This approach is known as 'innovation-driven' growth (e.g. Andolfatto and MacDonald, 1998; Jovanovic and MacDonald, 1994). Next to technogenesis, there is increasing attention for the follow-up trajectory, in principal dissemination channels and technology adoption mechanisms; a process of paramount importance. But how can this process be measured? The term 'technology adoption' appears to mean many things to many people, and a great number of theoretical/empirical approaches have been used to account for this process. Following Romer (1990), technological change in an economy is the result of the number of workers employed in innovative and technologically advanced sectors. Along those lines, several authors use a parallel way to approximate the process of technology adoption. ${ }^{3}$ Closely related to this argument is the contribution of advanced and dynamic technological sectors in driving the process of technology adoption. In other words, this approach involves identifying those sectors which are perceived to be the most receptive to innovation and its utilization. From this perspective, such sectors act as the 'leading' sectors in an economy (e.g. Dosi et al., 1988, 1990; Cohen and Levinthal, 1990). This view accepts the argument that 'leading' sectors promote the evolution of the economy as a whole, which constitutes also our point of departure. The underlying motivation for our study stems from an 'input-approach' model based on the premise that the process of technology adoption is reflected through the impact of an exogenous technological shock on employment in leading sectors. We should emphasize at the outset that the technological shock is assumed to be exogenously determined since our primary concern is to elaborate upon the mechanics of technology adoption, rather than to study the impact of this process on economic growth. Therefore, it might prove more instructive to focus on the aftermath of a technological shock. The key to the understanding of this lies in a thorough comprehension of the nature of the impact on the human resources in leading sectors.

An exogenous technological shock results in an increase in relative sectoral productivity and induces workers with suitable abilities to be employed in technologically advanced sectors. This

\footnotetext{
${ }^{2}$ This approach stems from the earlier contribution of Schumpeter (1934). Even though frequently criticized (for a more detailed review, see Andersen, 1996), it has been widely applied in the recent literature on economic growth.

${ }^{3}$ For example Gripaios et al. (2000) select four high technology industries, as defined by the OECD: namely, aerospace, pharmaceuticals, TV-radio and communication equipment, and computer and office equipment. A similar sectoral selection is proposed in several other studies (e.g. Plummer and Taylor, 2001a; 2001b; Andonelli, 1990; Alderman, 2004; Alderman and Fischer, 1992).
} 
provides an alternative way forward in approximating technology adoption. To do so, a solid microeconomic 'tool-kit' is at our disposal: namely, 'search' theory ${ }^{4}$, which forms the central conceptual apparatus for our approach. This theory is well established in contemporary economics. Using this framework, Mortensen and Pissarides (1998, 1999), for example, examine the impact of, exogenous technological shocks on unemployment. However, the process of technology adoption itself is not examined in their study, at least not in an explicit way. ${ }^{5}$ Nevertheless, 'search' theory allows an alternative interpretation of the impact of an exogenous technological shock on the level of employment in skill-based (leading) sectors: namely, adoption of technology.

To complete this introduction, a final point is in order. This paper aims to make a contribution to the existing literature on the adoption of technology in relation underlying mechanisms by building upon 'search theory'. To the best of our knowledge, the application of such an approach is rather rare in the literature concerning the effects of technology adoption.

In order to achieve our aim, this paper is divided into four subsequent sections. The structure of the model is outlined in Section 2, while the transitional dynamics are examined in Section 3. Next, the theoretical framework is empirically tested using an extensive dataset from 10 OECD countries. Data related issues are discussed in Section 4, and the model is submitted to the usual econometric tests yielding the main findings. Section 5 concludes the paper, and suggests areas for further research.

\section{Modelling Technology Adoption in a 'Search and Match- ing' Framework}

\subsection{Structure of the Model}

A primary concern of this paper is to investigate the mechanisms of the technology adoption in a one-sided 'search-and-matching' context with a two-level ex-ante heterogeneity of workers. ${ }^{6}$ Given that the adoption of technology can be encapsulated in the employment in 'leading' sectors, it is more appropriate to consider a 'sectoral' approach. In other words, the economy is subdivided into

\footnotetext{
${ }^{4}$ For a more detailed survey see Rogerson et al. (2005)

${ }^{5}$ Some interesting aspects of technology adoption can be found in the work of Linn (2008) concerning energysaving technologies while Bandiera and Rasul (2006) examine the process of technology adoption in agriculture. Weel (2006) attempts to introduce the issue of technology diffusion in a context of labour market dynamics. This analysis however, is mainly empirical without an explicit theoretical background.

${ }^{6}$ The efficiency of a similar two-sided search model has been examined recently by Eleftheriou (2010). However, the aspect of technology adoption is not examined in this framework.
} 
two sectors, a 'traditional' and a 'leading' one. In this model, total production in the economy is undertaken by two sectors, labelled by 1 and 2 . It becomes of crucial importance, therefore, to determine which is the leading sector of the economy. Although there is a multiplicity of criteria identifying a sector as 'leading' in the present context, it suffices to state that the distinctive feature between the two sectors is defined in terms of productivity. Assuming that the leading sector offers more facilities, then workers with equal skills/abilities will be more productive in the 'leading' sector, relative to the 'traditional' one. This assumption has important implications for analyzing the effects of an, exogenously, determined technological shock ${ }^{7}$ that increases the level of relative productivity. Prior to this, however, some assumptions that characterize the labour market of the economy are necessary. To be more precise, we assume a discrete-time, one-sided search model of the labour market ${ }^{8}$ with risk neutral and infinite-lived workers. The number of workers participating in the market is normalized to unity. Each individual is endowed with a two-dimensional skill vector ${ }^{9}$ $a=\left[\begin{array}{c}a_{1} \\ a_{2}\end{array}\right]$, where $a_{1}$ and $a_{2}$ are independent random variables, uniformly distributed over the interval $[0,1]$. An individual with a skill vector $a$ employed in Sector $i$ has a level of productivity, which we subsequently denote as $k_{i} a_{i}, i \in\{1,2\}$, with $k_{i}=k>1$ if $i=1$ and $k_{i}=1$ if $i=2$. The parameter $k$ is a pre-determined factor that augments relative productivity between the two sectors. Given that productivity is higher in Sector 1 relative to Sector 2, it follows that the former sector can be conceived as the 'leading' sector of the economy, which is ensured by the assumption that $k>1$. Acknowledging the idea that a technological shock induces an increase in $k$, it is reasonable to assume that this will have an impact upon the employment decisions of workers in each sector. In order to proceed further however, some additional assumptions are necessary. The rate at which a worker gets an offer to work in Sector 1 is $\beta \varphi$, where $\beta \in(0,1)$ is a Poisson arrival rate of a job offer, while $\varphi$ is the probability that this offer comes from Sector 1 (stated alternatively, $\operatorname{Pr}\left(S_{1} \mid S_{1}\right.$ $\left.\cup S_{2}\right)=\varphi$, where $S_{1}$ and $S_{2}$ denote the event of an offer from Sector-1 and Sector-2, respectively). Hence, a worker gets a job offer in Sector 2 at a rate $\beta(1-\varphi)$. There is no on-the-job search; individuals cannot be employed simultaneously in both sectors; and they can be either in a state of employment or unemployment. Workers and firms discount the future at the same rate $r$, while

\footnotetext{
${ }^{7} \mathrm{~A}$ 'technological shock' may occur within an economy, i.e. endogenously. However, our perspective is the process through which a technological shock is absorbed and diffused across the sectors of an economy.

${ }^{8}$ An early treatment of such model can be found in McCall (1970).

${ }^{9}$ This assumption incorporates the notion of skill 'bundling'. A more detailed exposition of this notion, together with its implications in workers' decisions, can be found in the early work of Roy (1951) and its subsequent extensions by Heckman and Sedlacek (1985) and Heckman and Scheinkman (1987).
} 
the lay-off rate is exogenously determined and equal to $\delta$, with $\delta, r \in[0,1]$. A final assumption is that the flow value of leisure, $b$, is equal to zero. ${ }^{10}$

\subsection{Decision Making, Classification of Individuals and Reservation In- come}

Maintaining the 'search' theory as the basic vehicle of analysis, the process of individuals' decision making can be described as follows: Let $U(a)$ be the value of unemployment for an individual endowed with skills $a_{1}, a_{2}$, and $W_{i}(a)$ denote the value of being employed in Sector $i$.

The Bellman equation for the value of unemployment for a worker with skills $a_{1}, a_{2}$ is written as follows:

$$
r U(a)=\beta \varphi \max \left[W_{1}(a)-U(a), 0\right]+\beta(1-\varphi) \max \left[W_{2}(a)-U(a), 0\right]
$$

The respective value of employment for a worker with skill vector $a$ in Sector $i$ is given by:

$$
r W_{i}(a)=k_{i} a_{i}+\delta\left[U(a)-W_{i}(a)\right]
$$

The assumption that the labour market is characterized by perfect competition is made explicit by equation (2), and consequently workers are paid their marginal products. More formally, the lefthand-side of equation (2) indicates the flow value of being employed, $k_{i} a_{i}$ is the wage/productivity; and the product of the lay-off rate $(\delta)$ with the difference of being employed and unemployed $\left(\left[U(a)-W_{i}(a)\right]\right)$ constitutes the instantaneous capital loss from a job separation. Thus, individuals form reservation values for $a_{1}, a_{2}$; if there is a capital gain from changing states, defined as $W_{i}(a)-$ $U(a) \geq(<) 0$, then an individual will accept (reject) a job offer in Sector $i$. More specifically, an individual with ability vector $a$ will accept a job in Sector $i$, if and only if $k_{i} a_{i} \geq r U(a)$; an outcome that can be derived using equation (2). If $k a_{1} \geq(<) a_{2}$ and the latter condition holds for $a_{2}\left(k a_{1}\right)$, then this will hold for $k a_{1}\left(a_{2}\right)$ too.

Lemma 1 Workers will always accept at least one type of job

\footnotetext{
${ }^{10}$ This assumption is necessary in order to avoid the existence of individuals who do not participate in the labour market. Such a restriction can be considered as a participation constraint. Imposing a value of $b \neq 0$ accounts for workers who do not participate in the labour market, i.e. discouraged workers. This however, does not alter the generalization of the model, as far as the process of technology adoption is concerned.
} 
Proof. Assume that $k a_{1} \geq(<) a_{2}$. This implies that, if $W_{1}(a)<U(a)\left(W_{2}(a)<U(a)\right)$, then $W_{2}(a)<U(a)\left(W_{1}(a)<U(a)\right)$. If $W_{1}(a)<U(a)\left(W_{2}(a)<U(a)\right)$, then using equation (1), $r U(a)=0$. This, with the aid of $(2)$, yields: $W_{1}(a)<U(a)\left(W_{2}(a)<U(a)\right)$ if $a_{1}\left(a_{2}\right)<0$. However, by definition this does not hold. Q.E.D.

Lemma 2 Individuals accept only Sector 1 (2) jobs if and only if $a_{2} \leq a_{2 R}\left(a_{1}\right)=\frac{\beta \varphi k a_{1}}{\beta \varphi+r+\delta}\left(a_{1} \leq\right.$ $\left.a_{1 R}\left(a_{2}\right)=\frac{\beta(1-\varphi) a_{2}}{[r+\delta+\beta(1-\varphi)] k}\right)$, where $0 \leq a_{1} \leq 1\left(0 \leq a_{2} \leq 1\right)$

Proof. Bearing in mind the discussion above and Lemma 1, a value of $a_{2}=a_{2 R}$ has to be determined such that ensures the identity $W_{2}(a)=U(a)$, which by substituting into equation (2), yields:

$$
W_{2}(a)=U(a)=a_{2 R} / r
$$

Using (1), (2) and (3) gives $a_{2 R}\left(a_{1}\right)=\frac{\beta \varphi k a_{1}}{\beta \varphi+r+\delta}$. A similar process can be implemented to show that $a_{1 R}\left(a_{2}\right)=\frac{\beta(1-\varphi) a_{2}}{[r+\delta+\beta(1-\varphi)] k}$. Q.E.D.

To sum up, individuals can be classified into three categories:

i) Individuals with $0 \leq a_{1} \leq \hat{a}_{1}, a_{2 R}<a_{2}<a_{1 R}^{-1}$; and $\hat{a}_{1}<a_{1} \leq 1, a_{2 R}<a_{2}<1$, accept Sector 1 and Sector 2 jobs $^{11}$;

ii) Individuals with $0 \leq a_{1} \leq 1,0 \leq a_{2} \leq a_{2 R}$ accept only Sector 1 jobs;

iii) Individuals with $0 \leq a_{2} \leq 1,0 \leq a_{1} \leq a_{1 R}$, accept only Sector 2 jobs.

Figure 1 illustrates those categories. The horizontal axis measures $a_{1}$, while $a_{2}$ are in the vertical axis. Generally, points close to axis $a_{1}\left(a_{2}\right)$ indicate that workers are more specialized in Sector 1 (2). Along the grey solid line $a_{2}=k a_{1}$. Workers below (above) that line are more (less) productive in the 'leading' Sector 1. The solid black line is the graph of $a_{1 R}^{-1}$, and the dashed line is the graph of $a_{2 R}$. Workers with $a_{1}, a_{2}$, below $a_{2 R}$ accept jobs only in Sector 1, i.e. the sector in which they are specialized. Similarly, as our assumptions require, individuals with $a_{1}, a_{2}$, above $a_{1 R}^{-1}$ accept only Sector 2 jobs, a sector in which they are more productive. On the other hand, the area between the $a_{1 R}^{-1}$ and $a_{2 R}$ lines indicates the possibility of a mismatch. ${ }^{12}$ In particular, although workers in the area between the lines $a_{1 R}^{-1}$ and $a_{2}=k a_{1}$ accept offers from both sectors and although they are more productive in Sector 2, there is a possibility to find themselves working in Sector 1 . The

\footnotetext{
${ }^{11}$ where $a_{1 R}^{-1}$ is the inverse function of $a_{1 R}, \hat{a}_{1}=\frac{\beta(1-\varphi)}{[r+\delta+\beta(1-\varphi)] k}$ and $\left.a_{1 R}^{-1}\left(\hat{a}_{1}\right)=1\right)$.

${ }^{12}$ For an alternative view of mismatch situation within a labour market matching model with heterogenous workers, see Mukoyama and Şahin (2009).
} 
situation in which workers specialized in Sector 1, accept job offers from both sectors, but they may work in Sector 2 is indicated by the area between the lines $a_{2}=k a_{1}$ and $a_{2 R}$. One further point is worth noting in Figure 1. An exogenous technological shock brings an increase in $k$, which will rotate all lines upwards along the origin. The area below $a_{2 R}$ will increase, while the area above $a_{1 R}^{-1}$ will decrease. In other words, this signifies an increase in the workers who accept offers only from the leading Sector 1. This, together with a decrease in the workers who accept offers only from Sector 2, can be considered an approximation of the adoption of technology by the economy that will, eventually, lead to a new steady state; a situation of particular interest which is examined next.

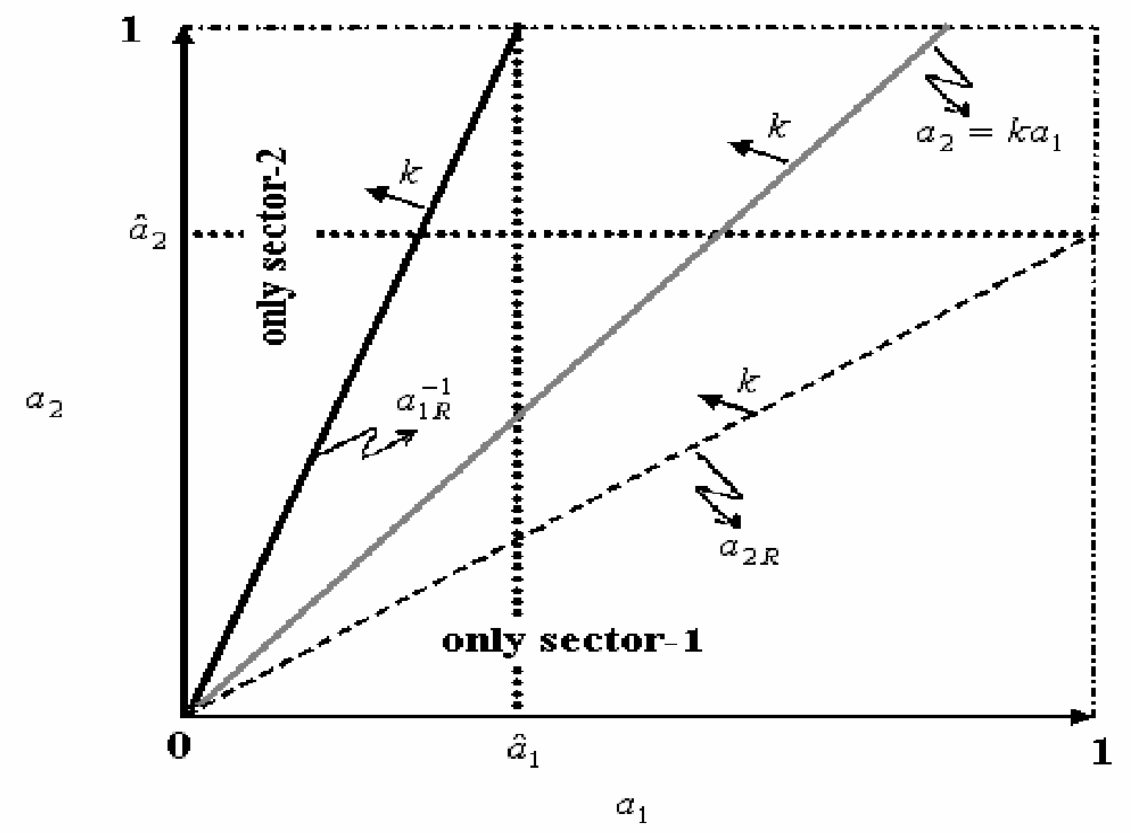

Figure 1: Employment Possibilities in a Two Sector Economy with Two Levels of Ex ante Heterogeneity 


\section{Transition Dynamics and Steady States}

What is the aftermath of a 'technological shock' in the steady state of the economy portrayed above? As argued in the previous section, a 'technological shock' can be deemed as an increase in the key element of the model, $k$. Combining this with the assumption that Sector 1 is the leading sector, such a shock is biased towards this sector, and as a result the productivity of Sector 1 will be increased relative to Sector 2. The critical question, however, as far the process of technology adoption is concerned, is how workers will react as a result of a technological shock. Given Lemma 1 and 2, a Sector 1 biased 'technology shock' leads to the following result:

RESULT 1. A Sector 1 biased technology shock increases (reduces) $a_{2 R}\left(a_{1 R}\right)$ : namely, more (less) individuals prefer to work only in Sector 1(2).

Let $\lambda_{t}(a)$ and $g_{t}(a)$ be the densities of unemployed and employed individuals with skill vector $a$ at time $t$, respectively, satisfying the restriction $f(a)=\lambda_{t}(a)+g_{t}(a)$, where $f(a)=1$ is the density of the total population. Throughout time, unemployed individuals with $0 \leq a_{1} \leq 1,0 \leq a_{2} \leq a_{2 R}$, are employed at rate $\beta \varphi$, whereas a fraction $\delta$ of them become unemployed. In this light, $g_{t}(a)+$ $\beta \varphi \lambda_{t}(a)-\delta g_{t}(a)$ is the stock of employed individuals with $0 \leq a_{1} \leq 1,0 \leq a_{2} \leq a_{2 R}$, at the end of a given time period. A similar approach can be used to define the stocks of employed individuals

with $0 \leq a_{2} \leq 1,0 \leq a_{1} \leq a_{1 R}$ and $0 \leq a_{1} \leq \hat{a}_{1}, a_{2 R}<a_{2}<a_{1 R}^{-1}$ and $\hat{a}_{1}<a_{1} \leq 1, a_{2 R}<a_{2}<1$. Thus, the stock of employed individuals with skill vector $a$ evolves as follows:

$$
g_{t+1}(.)=\left\{\begin{array}{c}
(1-\delta-\beta \varphi) g_{t}(.)+\beta \varphi f(.), \text { for } 0 \leq a_{1} \leq 1,0 \leq a_{2} \leq a_{2 R} \\
(1-\delta-\beta) g_{t}(.)+\beta f(.), \text { for } 0 \leq a_{1} \leq \hat{a}_{1}, a_{2 R}<a_{2}<a_{1 R}^{-1} \\
\text { and } \hat{a}_{1}<a_{1} \leq 1, a_{2 R}<a_{2}<1 \\
{[1-\delta-\beta(1-\varphi)] g_{t}(.)+\beta(1-\varphi) f(.), \text { for } 0 \leq a_{2} \leq 1,0 \leq a_{1} \leq a_{1 R}}
\end{array}\right.
$$

Consider an initial distribution $g_{0}($.$) . Solving the set of difference equations in (4), the$ evolution of the distribution function $g_{t}($.$) is written as follows:$ 


$$
g_{t}(.)=\left\{\begin{array}{c}
(1-\delta-\beta \varphi)^{t} g_{0}(.)+\left[1-(1-\delta-\beta \varphi)^{t}\right] \frac{\beta \varphi}{\beta \varphi+\delta} f(.) \\
\text { for } 0 \leq a_{1} \leq 1,0 \leq a_{2} \leq a_{2 R} \\
\rho^{t} g_{0}(.)+\left[1-\rho^{t}\right] \xi f(.) \\
\text { for } 0 \leq a_{1} \leq \hat{a}_{1}, a_{2 R}<a_{2}<a_{1 R}^{-1} \text { and } \hat{a}_{1}<a_{1} \leq 1, a_{2 R}<a_{2} \leq 1 \\
{[1-\delta-\beta(1-\varphi)]^{t} g_{0}(.)+\left[1-(1-\delta-\beta(1-\varphi))^{t}\right] \frac{\beta(1-\varphi)}{\beta(1-\varphi)+\delta} f(.)} \\
\text { for } 0 \leq a_{1} \leq \hat{a}_{1}, 1 \geq a_{2} \geq a_{1 R}^{-1}
\end{array}\right.
$$

where $\rho=(1-\beta-\delta)$ and $0<\xi=\frac{\beta}{\beta+\delta} \leq 1$.

Equation (5) implies that $g_{t} \rightarrow g$, as $t \rightarrow \infty$. Consequently, the steady-state distribution of employed individuals $g$ is defined in the following terms:

$$
g(.)=\left\{\begin{array}{c}
\frac{\beta \varphi}{\beta \varphi+\delta} f(.), \text { for } 0 \leq a_{1} \leq 1,0 \leq a_{2} \leq a_{2 R} \\
\xi f(.), \text { for } 0 \leq a_{1} \leq \hat{a}_{1}, a_{2 R}<a_{2}<a_{1 R}^{-1} \\
\text { and } \hat{a}_{1}<a_{1} \leq 1, a_{2 R}<a_{2}<1 \\
\frac{\beta(1-\varphi)}{\beta(1-\varphi)+\delta} f(.), \text { for } 0 \leq a_{2} \leq 1,0 \leq a_{1} \leq a_{1 R}
\end{array}\right.
$$

Another related issue to be considered is the long-run employment in each sector. This can be determined by the steady state distribution of employed individuals. To be more precise, equation (7) gives the individuals employed in Sector 1 in steady state:

$$
\begin{aligned}
N_{1}= & \int_{0}^{1} \int_{0}^{a_{2 R}}[(\beta \varphi) /(\beta \varphi+\delta)] d a_{2} d a_{1}+ \\
& \varphi\left\{\int_{0}^{\hat{a}_{1}} \int_{a_{2 R}}^{a_{1 R}^{-1}} \xi d a_{2} d a_{1}+\int_{\hat{a}_{1}}^{1} \int_{a_{2 R}}^{1} \xi d a_{2} d a_{1}\right\}
\end{aligned}
$$

Similarly, employment in Sector 2 will be:

$$
\begin{aligned}
N_{2}= & \int_{0}^{1} \int_{0}^{a_{1 R}}[(\beta(1-\varphi)) /(\beta(1-\varphi)+\delta)] d a_{1} d a_{2}+ \\
& (1-\varphi)\left\{\int_{0}^{\hat{a}_{2}} \int_{a_{1 R}}^{a_{2 R}^{-1}} \xi d a_{1} d a_{2}+\int_{\hat{a}_{2}}^{1} \int_{a_{1 R}}^{1} \xi d a_{1} d a_{2}\right\}
\end{aligned}
$$


where $a_{2 R}^{-1}$ is the inverse function of $a_{2 R}$ and $\hat{a}_{2}=\frac{\beta \varphi k}{\beta \varphi+r+\delta}$ with $a_{2 R}^{-1}\left(\hat{a}_{2}\right)=1$.

Output in Sectors 1 and 2 in the steady-state are given by equations (9) and (10), respectively:

$$
\begin{aligned}
Y_{1}=k & {\left[\begin{array}{c}
\int_{0}^{1} \int_{0}^{a_{2 R}} a_{1}[(\beta \varphi) /(\beta \varphi+\delta)] d a_{2} d a_{1}+ \\
\varphi\left\{\int_{0}^{\hat{a}_{1}} \int_{a_{2 R}}^{a_{1 R}^{-1}} a_{1} \xi d a_{2} d a_{1}+\int_{\hat{a}_{1}}^{1} \int_{a_{2 R}}^{1} a_{1} \xi d a_{2} d a_{1}\right\}
\end{array}\right] } \\
Y_{2}= & \int_{0}^{1} \int_{0}^{a_{1 R}} a_{2}[(\beta(1-\varphi)) /(\beta(1-\varphi)+\delta)] d a_{1} d a_{2}+ \\
& (1-\varphi)\left\{\int_{0}^{\hat{a}_{2}} \int_{a_{1 R}}^{a_{2 R}^{-1}} a_{2} \xi d a_{1} d a_{2}+\int_{\hat{a}_{2}}^{1} \int_{a_{1 R}}^{1} a_{2} \xi d a_{1} d a_{2}\right\}
\end{aligned}
$$

It can be easily shown that $N_{1}, Y_{1}$ increase in $k$, whereas $N_{2}, Y_{2}$ decrease in $k$.

Once this knowledge is introduced, the next important step forward is to describe the transition process of sectoral employment and output after a Sector 1 biased technological shock. Thus,

$$
\begin{aligned}
N_{1 t}= & \int_{0}^{1} \int_{0}^{a_{2 R}} \frac{\beta \varphi}{\beta \varphi+\delta} d a_{2} d a_{1}+ \\
& \int_{0}^{1} \int_{a_{2 R}}^{a_{2 R}^{\prime}}\left\{[1-\delta-\beta \varphi]^{t} \frac{\beta \varphi}{\beta+\delta}+\left[1-(1-\delta-\beta \varphi)^{t}\right] \frac{\beta \varphi}{\beta \varphi+\delta}\right\} d a_{2} d a_{1}+ \\
\varphi & {\left[\begin{array}{c}
\left.\int_{0}^{\hat{a}_{1}} \int_{a_{2 R}^{\prime}}^{a_{1 R}^{-1}} \xi d a_{2} d a_{1}+\int_{0}^{\hat{a}_{1}^{\prime}} \int_{a_{1 R}^{-1}}^{a_{1 R}^{-1}}\left[1-\rho^{t}\right] \xi d a_{2} d a_{1}+\right] \\
\int_{\hat{a}_{1}^{\prime}}^{\hat{a}_{1}} \int_{a_{1 R}^{-1}}^{1}\left[1-\rho^{t}\right] \xi d a_{2} d a_{1}+\int_{\hat{a}_{1}}^{1} \int_{a_{2 R}^{\prime}}^{1} \xi d a_{2} d a_{1}
\end{array}\right] } \\
N_{2 t}= & \int_{0}^{1} \int_{0}^{a_{1 R}^{\prime}} \frac{\beta(1-\varphi)}{\beta(1-\varphi)+\delta} d a_{1} d a_{2}+ \\
& \int_{0}^{1} \int_{a_{1 R}^{\prime}}^{a_{1 R}}\left\{\rho^{t} \frac{\beta(1-\varphi)}{\beta(1-\varphi)+\delta}+\left(1-\rho^{t}\right) \frac{\beta(1-\varphi)}{\beta+\delta}\right\} d a_{1} d a_{2}+ \\
& (1-\varphi)\left[\int_{0}^{\hat{a}_{2}^{\prime}} \int_{a_{1 R}}^{a_{2 R}^{-1^{\prime}}} \xi d a_{1} d a_{2}+\int_{\hat{a}_{2}^{\prime}}^{1} \int_{a_{1 R}}^{1} \xi d a_{1} d a_{2}\right]
\end{aligned}
$$




$$
\begin{aligned}
& Y_{1 t}=\int_{0}^{1} \int_{0}^{a_{2 R}} k^{\prime} a_{1} \frac{\beta \varphi}{\beta \varphi+\delta} d a_{2} d a_{1}+ \\
& \int_{0}^{1} \int_{a_{2 R}}^{a_{2 R}^{\prime}} k^{\prime} a_{1}\left\{[1-\delta-\beta \varphi]^{t} \frac{\beta \varphi}{\beta+\delta}+\left[1-(1-\delta-\beta \varphi)^{t}\right] \frac{\beta \varphi}{\beta \varphi+\delta}\right\} d a_{2} d a_{1}+ \\
& \varphi\left[\begin{array}{l}
\int_{0}^{\hat{a}_{1}} \int_{a_{2 R}^{\prime}}^{a_{1 R}^{-1}} k^{\prime} a_{1} \xi d a_{2} d a_{1}+\int_{0}^{\hat{a}_{1}^{\prime}} \int_{a_{1 R}^{-1}}^{a_{1 R}^{-1^{\prime}}} k^{\prime} a_{1}\left[1-\rho^{t}\right] \xi d a_{2} d a_{1} \\
+\int_{\hat{a}_{1}^{\prime}}^{\hat{a}_{1}} \int_{a_{1 R}^{-1}}^{1} k^{\prime} a_{1}\left[1-\rho^{t}\right] \xi d a_{2} d a_{1}+\int_{\hat{a}_{1}}^{1} \int_{a_{2 R}^{\prime}}^{1} k^{\prime} a_{1} \xi d a_{2} d a_{1}
\end{array}\right] \\
& Y_{2 t}=\int_{0}^{1} \int_{0}^{a_{1 R}^{\prime}} a_{2} \frac{\beta(1-\varphi)}{\beta(1-\varphi)+\delta} d a_{1} d a_{2}+ \\
& \int_{0}^{1} \int_{a_{1 R}^{\prime}}^{a_{1 R}} a_{2}\left\{\rho^{t} \frac{\beta(1-\varphi)}{\beta(1-\varphi)+\delta}+\left(1-\rho^{t}\right) \frac{\beta(1-\varphi)}{\beta+\delta}\right\} d a_{1} d a_{2}+ \\
& (1-\varphi)\left[\int_{0}^{\hat{a}_{2}^{\prime}} \int_{a_{1 R}}^{a_{2 R}^{-1^{\prime}}} a_{2} \xi d a_{1} d a_{2}+\int_{\hat{a}_{2}^{\prime}}^{1} \int_{a_{1 R}}^{1} a_{2} \xi d a_{1} d a_{2}\right]
\end{aligned}
$$

where $k^{\prime}>k$ and $a_{2 R}^{\prime}=\frac{\beta \varphi k^{\prime} a_{1}}{\beta \varphi+r+\delta}, a_{1 R}^{-1^{\prime}}=\frac{[\beta(1-\varphi)+r+\delta] k^{\prime} a_{1}}{\beta(1-\varphi)}, \hat{a}_{1}^{\prime}=\frac{\beta(1-\varphi)}{[r+\delta+\beta(1-\varphi)] k^{\prime}}, a_{1 R}^{\prime}=\frac{\beta(1-\varphi) a_{2}}{[\beta(1-\varphi)+r+\delta] k^{\prime}}, a_{2 R}^{-1^{\prime}}=$ $\frac{[\beta \varphi+r+\delta] a_{2}}{\beta \varphi k^{\prime}}, \hat{a}_{2}^{\prime}=\frac{\beta \varphi k^{\prime}}{\beta \varphi+r+\delta}$.

The model developed so far, implies three further important results: ${ }^{13}$

RESULT 2. Following a Sector 1 biased technological improvement, the new steady state is characterized by: (i) greater employment level and output in Sector 1 and lower employment level and output in Sector 2 (ii) increased aggregate output.

This result is of particular importance for describing the process of technology adoption since it implies that even if employment in the 'traditional' sector decreases as a result of the shock, the total output of the economy will be increased.

RESULT 3. In the impact period of a Sector 1 biased technological advance: (i) employment in Sector 1 declines relative to the trend (and remains unchanged absolutely); (ii) output in Sector 1 declines relative to the trend (and rises absolutely); (iii) employment and output in Sector 2 rises relative to the trend (and declines absolutely).

RESULT 4. Following the impact period of a Sector 1 biased technological advancement: Sectoral employment and output converge monotonically to the new steady state.

\footnotetext{
${ }^{13}$ See the Appendix for a more detailed mathematical treatment.
} 
Using reasonable values for the parameters of the model: namely, $\beta=0.7, \varphi=0.2, r=0.05$, $\delta=0.2, k=1.1$ and $k^{\prime}=1.3$, it is possible to illustrate the above results schematically. To be more specific, Results 2 and 3 can be depicted by a set of five Figures (2-6). Time is measured in the horizontal axis. The shock takes place during the period $t=0$. Time periods previous (after) to this shock are indicated by negative (positive) numbers. The aftermath of the shock, as encapsulated by the Result 4, is depicted by Figures 7 to 10, which elucidate the convergence behavior of the Sectoral employment and output towards the new steady state.

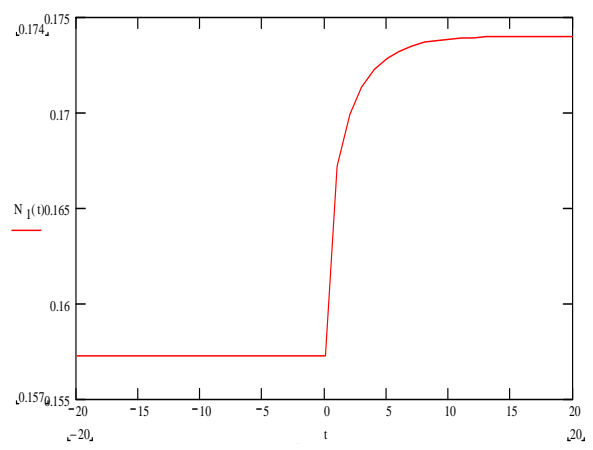

Figure 2. Employment in Sector 1,

Before and After the Shock

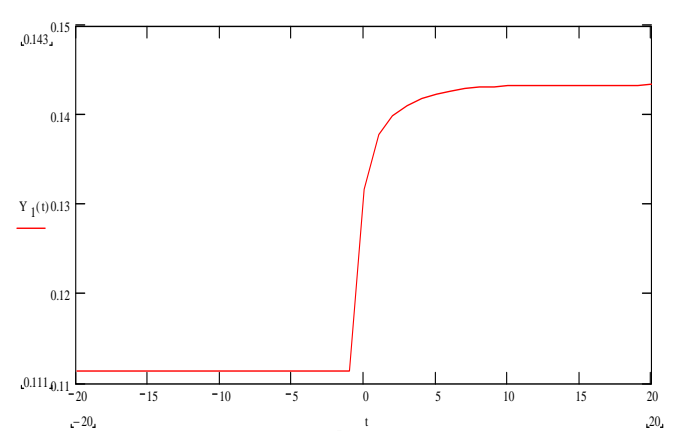

Figure 4. Output in Sector 1, Before and After the shock

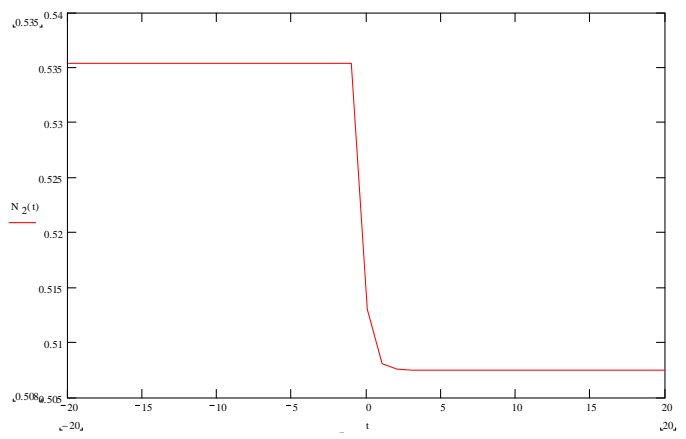

Figure 3. Employment in Sector 2, Before and After the Shock

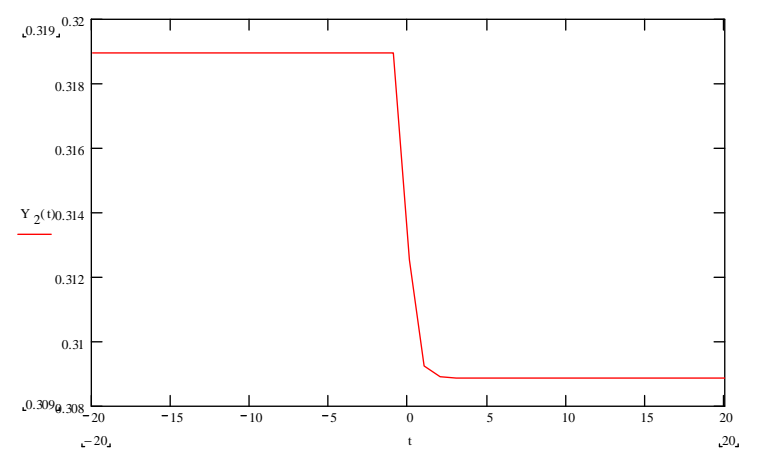

Figure 5. Output in Sector 2, Before and After the Shock 


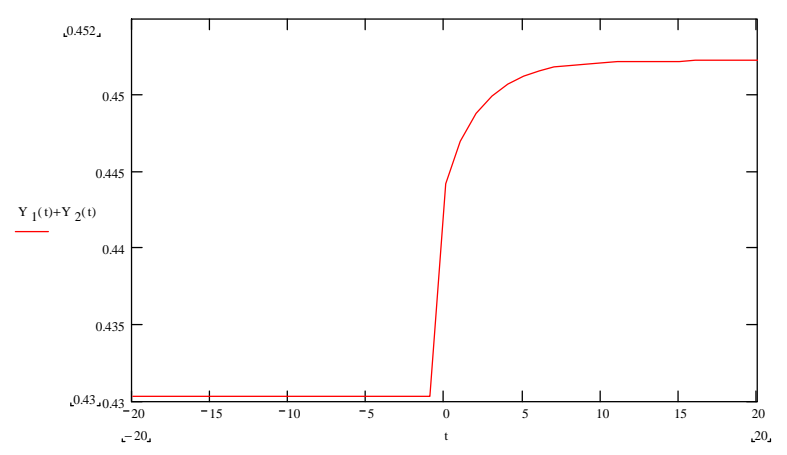

Figure 6. Total Output, Before and After the Shock

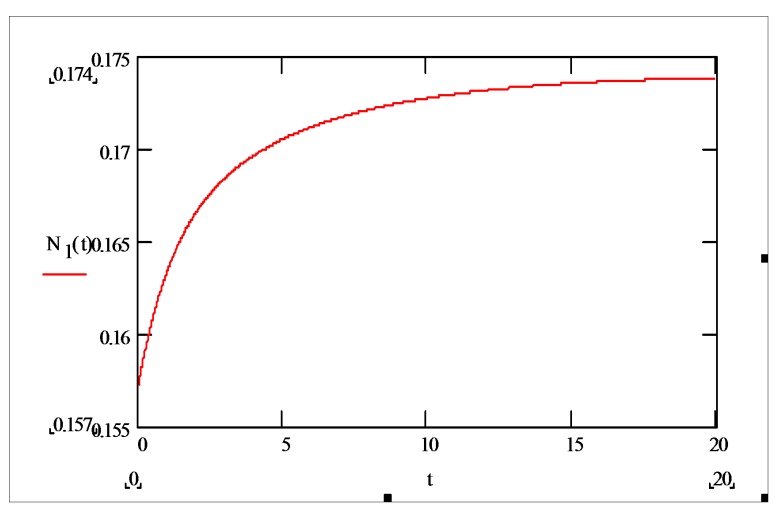

Figure 7. Convergence towards a New Steady state: Employment in Sector 1

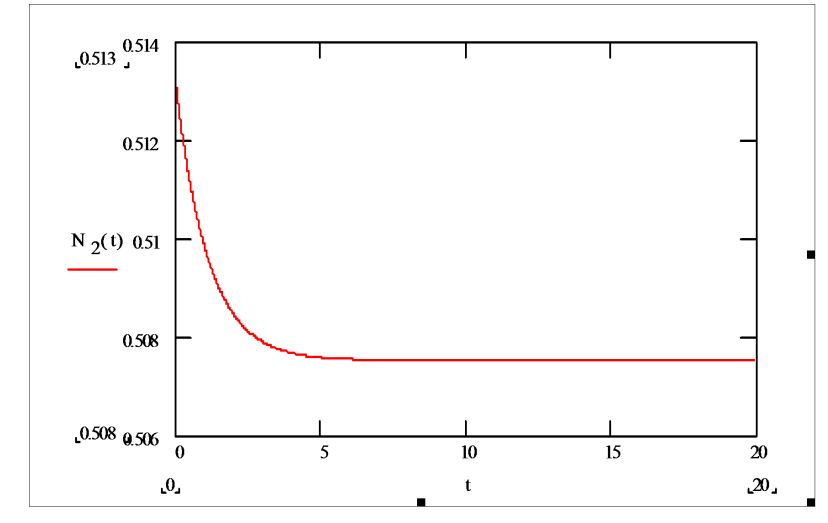

Figure 8. Convergence towards a New Steady State: Employment in Sector 2 


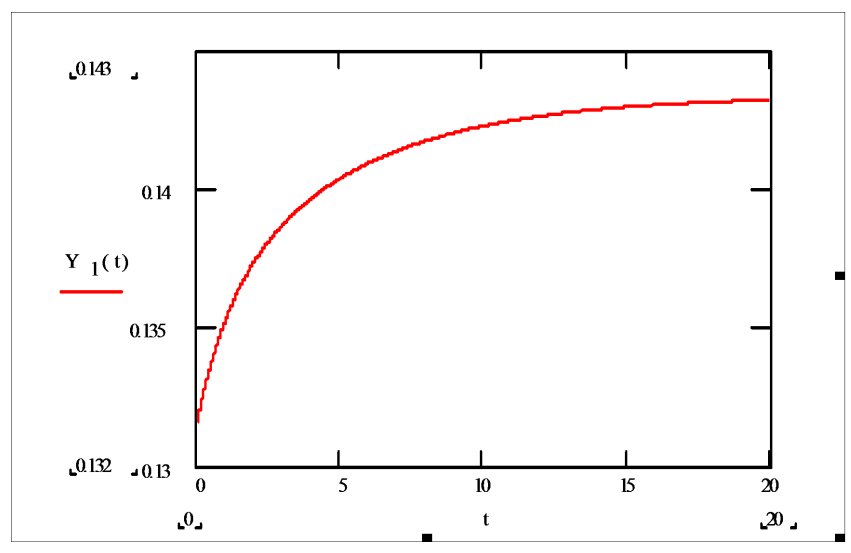

Figure 9. Convergence towards a New Steady State:

Output in Sector 1

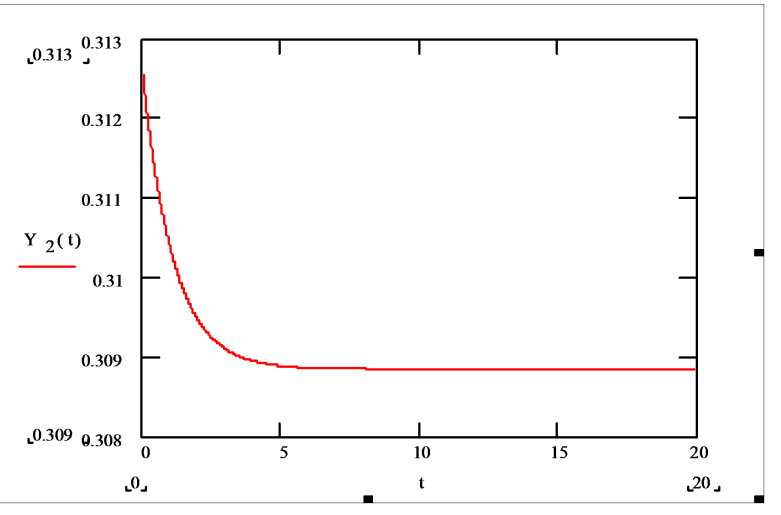

Figure 10. Convergence towards a New Steady State: Output in Sector 2

The impact of a technological shock results to a new steady state, in which employment increases in the leading sector. More specifically, the sequence of the decision process of workers can be described as follows. The technological shock will increase the relative productivity and, hence, the reservation values in favour of Sector 1. This implies that the number of individuals accepting job offers only from Sector 1 increases, while a fraction of individuals, previously accepting employment only from Sector 2, are now indifferent. Clearly, a transfer of resources from Sector 2 to Sector 1 is taking place. The extent of this transfer can be conceived as a measure of technology adoption in an economy.

\section{Econometric Application: 10 OECD Countries}

\subsection{Empirical Specification}

The conceptual model developed in the previous sections can be encapsulated in terms of a descriptive econometric model. In particular, we investigate the relation between employment in technologically advanced, and, by extension, leading sectors, and a variety of factors using an original data set covering selected OECD countries. The empirical aspect of the model adopts the following form:

$$
\ln \left(E_{i t}^{S 7}\right)=\gamma_{i t}+\gamma_{1} \ln \left(L H P I_{i t}\right)+\gamma_{2} \delta_{i t}+\gamma_{3} \beta_{i t}
$$


In equation (15), which, essentially, is an empirical approximation of equation $(7)^{14}, i$ refers to a given economy, and $t$ denotes a specific time period.

A scheme of measurement is developed to calibrate the dimensions of the model elaborated in the previous sections, and data for 10 OECD countries (Australia, Germany, France, Italy, Ireland, Spain, Portugal, Sweden, the UK and the USA) during the 1979-2007 period are used to develop a preliminary empirical analysis of the conditions that have been hypothesized as generating a process of technology adoption.

In equation (15), $E_{n t}^{S 7}$ stands for employment (in thousands persons) in seven leading sectors: chemicals, telecommunication equipment, radio and television receivers, scientific instruments, aircraft and spacecraft, computer and related activities, research and development. Following the structure of the model developed in Section 2, of particular importance is the change in the absolute level of employment in the advanced Sectors, rather than its change relative to the rest of the economy. The crucial variable of the model $(k)$ is approximated by $L H P I_{i t}$, which is a measure of relative productivity: namely, the ratio of productivity per-hours worked in the seven leading sectors relative to the remaining sectors of the economy, expressed in volume indices $(1995=100)$. According to the structure of our $k$ is permanent in nature and, consequently, the relevant variable can be approximated in terms of per-hours worked, as argued by Lindé (2009). Finally, $\delta_{i t}$ and $\beta_{i t}$ denote, respectively, the lay-off and outflow rate from unemployment.

The data on employment and productivity per hour were obtained from the Groningen Growth and Development Centre, '60-Industry Database'. ${ }^{15}$ Aggregation of the data for the seven technologically advanced Sectors and the rest of the economy was performed by the authors. ${ }^{16}$ It should be noted, however, that productivity can be expressed either in per person engaged or per hours worked. Nevertheless, two problems are associated with the former measure. First, there is an obvious multicollinearity problem. Second, and most important, there is the possibility that a technological shock might reduce the persons engaged, thus leading to biased results. However, this can be overcome if productivity is expressed in terms of per-hours worked (Lindé, 2009). Finally,

\footnotetext{
${ }^{14}$ In the empirical specification, two variables are not included: namely, the interest rate and the probability of a job offer from the leading sector $(\varphi)$. The absence of the former variable does not alter the results seriously, and the respective results are available upon request, while for the latter variable actual data are not available. Of course, a proxy can be constructed. However, this goes beyond the scope of this paper and constitutes an interesting topic for future research.

15 http://www.ggdc.net

${ }^{16}$ In case of missing values, linear extrapolation and interpolation techniques were utilized in order to complete the corresponding time-series.
} 
the lay-off and arrival rate for the countries included in the analysis were obtained from the data set constructed by Elsby et al. (2008). ${ }^{17}$

In operational terms, equation (15) is estimated using panel-data techniques. As is well known, there are three ways to perform panel-data estimations: namely, pooled ordinary least-squares, and fixed and random effects. According to the first way, both the constant term and the coefficients are treated as homogenous across time periods and observational units. In the present context, the latter are countries. Contrary, the fixed-effects technique assumes heterogeneity of the constant term over time and/or across countries. However, the effects associated with the countries can not be identified by this technique in the case of country-variant but time-invariant variables. This drawback can be overcome by using a random-effects specification, expressed in a general form as follows:

$$
\begin{gathered}
y_{i t}=c+\mathbf{b}^{\prime} \mathbf{x}_{i t}+\omega_{i t}(i=1, \ldots, n ; t=1, \ldots, T) \\
\text { s.t. } \omega_{i t}=\lambda_{i}+v_{t}+\varepsilon_{i t}
\end{gathered}
$$

where $\lambda_{i}$ stands for the unobserved individual-specific random effects, which are $\sim \operatorname{IID}\left(0, \sigma_{\lambda}^{2}\right)$; $v_{t}$ denotes the unobserved time-specific random effects, which are $\sim \operatorname{IID}\left(0, \sigma_{v}^{2}\right)$; and $\varepsilon_{i t}$ is the remaining error term which is distributed as $\sim \operatorname{IID}\left(0, \sigma_{\varepsilon}^{2}\right)$.

Equation (16) represents a two-way random-effects model, given that both time and individual specific error terms are included in $\omega_{i t}$. In this specification, the two error terms indicate the degree of deviation from the common intercept value.

Intuitively, the random effects model seems to be more appropriate. Nevertheless, its validity can be confirmed using two tests. First, we use a Lagrange multiplier $(L M)$ test proposed by Breusch and Pagan (1980) based on the combined time series $(t)$ and cross-sectional $(i)$ residuals $\left(\varepsilon_{i t}\right)$ from the pooled ordinary least squares regression. The null hypothesis of 'no-random effects' for this test is $H_{0}: \sigma_{\lambda}^{2}=\sigma_{\nu}^{2}=0$, and the associated statistic is calculated as follows:

$$
L M=\frac{n T}{2}\left\{\frac{1}{T-1}\left[\frac{\sum_{i=1}^{n}\left[\sum_{t=1}^{T} \varepsilon_{i t}\right]^{2}}{\sum_{i=1}^{n} \sum_{t=1}^{T} \varepsilon_{i t}^{2}}-1\right]^{2}+\frac{1}{n-1}\left[\frac{\sum_{t=1}^{T}\left[\sum_{i=1}^{n} \varepsilon_{i t}\right]^{2}}{\sum_{i=1}^{n} \sum_{t=1}^{T} \varepsilon_{i t}^{2}}-1\right]^{2}\right\}
$$

Under the null hypothesis, the LM statistic follows a chi-squared distribution with two degrees

\footnotetext{
${ }^{17}$ http://www.frbsf.org/economics/economists/bhobijn/UnemploymentDynamicsInTheOECD.xls
} 
of freedom.

Second, we use a test developed by Hausman (1978), which tests for orthogonality of the random effects by the generalized least squares (GLS) method and of the fixed effects by ordinary least squares (OLS). This test is based on the premise that, under the hypothesis of no correlation, both OLS and GLS are consistent, but OLS is inefficient. On the other hand, under the alternative hypothesis, OLS is consistent but GLS is not. Stated in alternative terms, the null hypothesis supports the fixed-effects model, while the alternative points to the superiority of the random effects model.

Calculating the associated values of these two tests, the random effects model is clearly indicated. To be more specific, the $L M$ statistic is 3,799.24. Given that at the 95 per-cent confidence level the critical value of $\chi^{2}(2)$ is 5.99 , the null hypothesis of 'fixed effects' is rejected. For the Hausman test, the estimated value of the Wald criterion is 79.42 , with a critical value of $\chi^{2}(2) \simeq 7.82$, providing additional support to the alternative hypothesis of random effects. In addition, the Hausman test indicates that our specification does not suffer from the inconsistency due to omitted variables.

Adopting this estimation method, regressing equation (15) produces the results shown in Table 1. On the whole, the model fits the data very well, given that all the explanatory variables are statistically significant. Generally, the econometric results imply a positive (negative) effect of the arrival (lay-off) rate on employment in the technologically advanced sectors for the countries included in our sample. This is a rather plausible result, as according to the structure of our model, an increase in the arrival (lay-off) rate induces a direct and an indirect effect. More precisely, the former indicates that individuals are able to change from the state of unemployment to employment relatively easily (with some difficulty) while the latter implies that, according to Lemma 2, individuals become more (less) picky, as far as employment choices are concerned, i.e. they reject more (less) job-offers from sectors in which they are relatively less specialized.

This econometric exercise offers fascinating insight. The message from the empirical application of the model developed in this paper is straightforward. Of critical importance for our study is the coefficient attached to the adoption parameter $\left(\gamma_{1}\right)$. Following the analysis in Section 2, it is expected that $\gamma_{1}>0$. According to the estimated results a 1 per cent increase in relative productivity, caused by an exogenous technological shock, will induce a 55 per cent increase, on average, in the labour force employed in the technologically advanced (leading) sectors. 


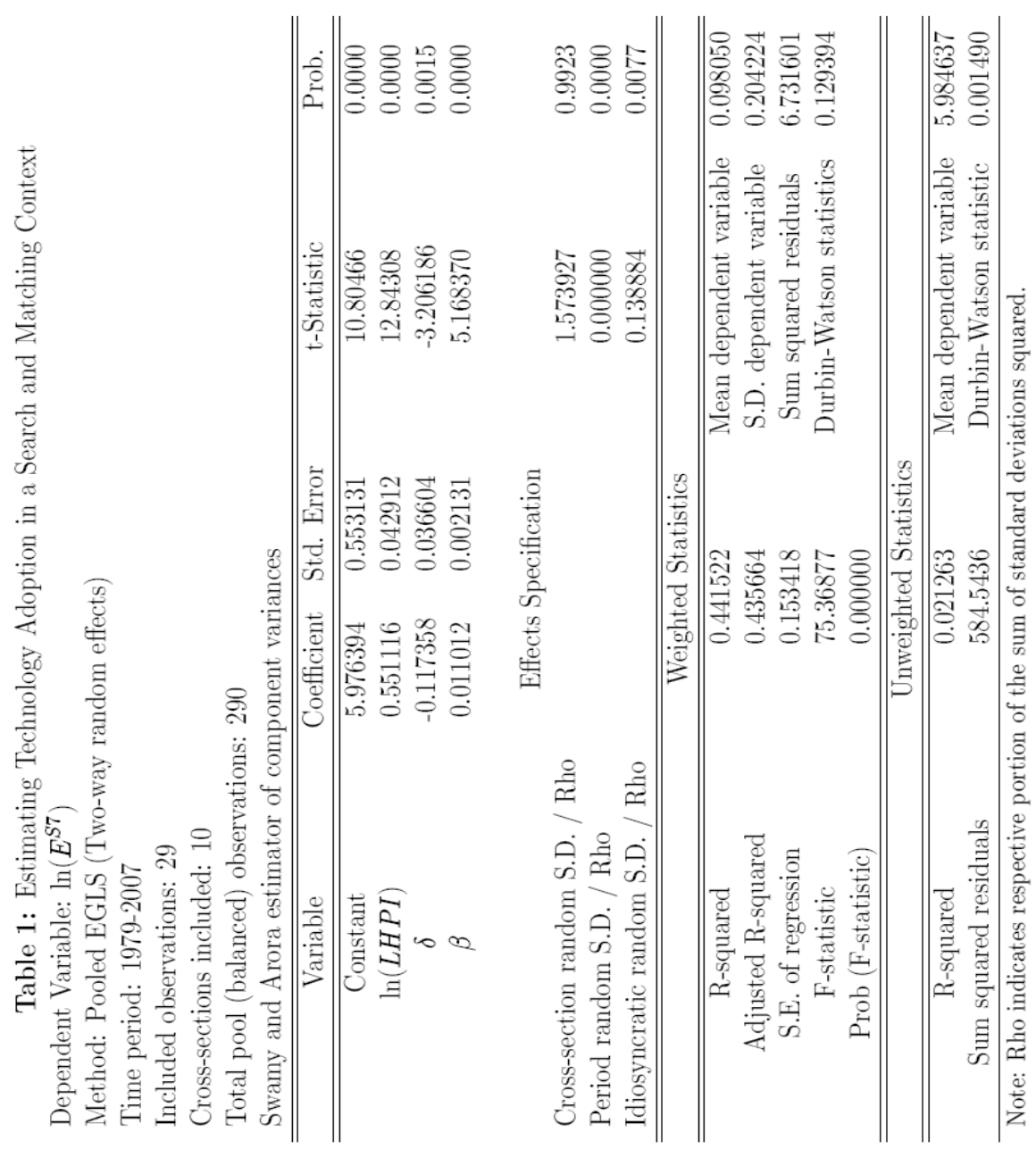




\section{Conclusion}

In this paper we have developed a model approximating technology adoption which implies that the probability for workers specialized in the leading sectors of the economy to be employed in such sectors is higher, following a technological shock. Eventually, this will cause an increase in the level of productivity in the economy as a whole. This process can be conceived as a reflection of technology adoption, which, by definition, constitutes an externality.

What we have attempted in this paper is to test empirically in a preliminary way the usefulness of this model. As in any modelling situation, we cannot know for certain whether a lack of correspondence between our theoretical presuppositions and the available empirical evidence is the result of the falsity of our target theory or the approximations and omissions that we employed in specifying the empirical model. Clearly much more work - both theoretical and especially empirical - needs to be undertaken before the issue of technology adoption can be discussed with confidence. Indeed, there is a need for more detailed and focused analysis with specific economies as case studies. Such research would help to build more realistic theory and more informed policy recommendations.

\section{References}

[1] Alderman, N. (2004). 'Innovation in Complex Capital Projects: Clustering and Dispersion in Two Cases from Argentina and the UK', Journal of Economic Geography, vol. 4 (1), pp. 65-82.

[2] Alderman, N. and Fischer, M. (1992). 'Innovation and Technological Change: An Australian Comparison', Environment and Planning A, vol. 24, pp. 273-288.

[3] Andersen, E. (1996). Evolutionary Economics: Post-Schumpeterian Contributions: Pinter.

[4] Andolfatto, D. and MacDonald, G. (1998). 'Technology Diffusion and Aggregate Dynamics', Review of Economic Dynamics, vol. 1(2), pp. 338-370.

[5] Andonelli, C. (1990). 'Induced Adoption and Externalities in the Regional Diffusion of Innovation Technology', Regional Studies, vol. 24 (1), pp. 31-40.

[6] Bandiera, O. and Rasul, I. (2006). 'Social Networks and Technology Adoption in Northern Mozambique', The Economic Journal, vol. 116, pp. 869-902. 
[7] Breusch, T. and Pagan, A. (1980). 'The Lagrange Multiplier Test and its Application to Model Specification in Econometrics', Review of Economic Studies, vol. 47, pp. 239-254.

[8] Cohen, W. and Levinthal, D. (1990). 'Absorptive capacity: a new perspective on learning and innovation', Administrative Science Quarterly, vol. 35 (1), pp.128-152.

[9] Dosi, G., Freeman, C. Nelson, R. Silverberg, G. and Soete, L. (1988). Technical Change and Economic Theory: Pinter.

[10] Dosi, G., Pavitt, K. and Soete, L. (1990). The Economics of Technical Change and International Trade: Harvester Wheatsheaf.

[11] Eleftheriou, K. (2010). 'Efficiency and Specialization: A Search Theoretic Approach', Forthcoming in Economic Modelling

[12] Elsby, M., Hobijn, B. and Sahin, A. (2008). 'Unemployment Dynamics in the OECD', NBER Working Papers 14617, National Bureau of Economic Research.

[13] Fine, B. (2000). 'Endogenous Growth Theory: A Critical Assessment', Cambridge Journal of Economics, vol. 24 (2), pp. 245-265.

[14] Gripaios, P., Bishop, P. and Keast, S. (2000). 'Differences in GDP per head in GB Counties: some Suggested Explanations', Applied Economics, vol. 32 (9), pp. 1161-1167.

[15] Hausman, J. (1978). 'Specification Tests in Econometrics', Econometrica, vol. 46 (6), pp. 12511271.

[16] Heckman, J., and Scheinkman, J. (1987). 'The Importance of Bundling in a Gorman-Lancaster Model of Earnings', Review of Economic Studies, vol. 54, pp. 243-255.

[17] Heckman, J., and Sedlacek, G. (1985). 'Heterogeneity, Aggregation, and Market Wage Functions: An Empirical Model of Self-Selection in the Labour Market', Journal of Political Economy, vol. 93, pp. 1077-1125.

[18] Jovanovic, B. and MacDonald, G. (1994). 'Competitive Diffusion', Journal of Political Economy, vol. 102 (1), pp. 24-52 
[19] Lindé, J. (2009). 'The effects of permanent technology shocks on hours: Can the RBC-model fit the VAR evidence?', Journal of Economic Dynamics and Control, vol. 33(3), pp. 597-613.

[20] Linn, J. (2008). 'Energy Prices and the Adoption of Energy Saving Technology', The Economic Journal, vol. 118, pp. 1986-2012.

[21] McCall, J. (1970). 'Economics of Information and Job Search', Quarterly Journal of Economics, vol. 84 , pp. 113-126.

[22] Mortensen, D. and Pissarides, C. (1998). 'Technological Progress, Job Creation and Job Destruction', Review of Economic Dynamics, vol. 1 (4), pp.733-753.

[23] Mortensen, D. and Pissarides, C. (1999). 'Unemployment Responses to 'Skill-Biased' Technology Shocks: The Role of Labour Market Policy', The Economic Journal, vol. 109 (455), pp.242-265.

[24] Mukoyama, T. and Şahin, A. (2009). 'Specialization and efficiency with labour-market matching', Journal of Economic Dynamics and Control, vol. 33, pp. 221-236.

[25] Pack, H. (1994). 'Endogenous Growth Theory: Intellectual Appeal and Empirical Shortcomings', Journal of Economic Perspectives, vol. 8 (1), pp. 55-72.

[26] Plummer, P. and Taylor, M. (2001a). 'Theories of Local Economic Growth: Part 1: Concepts, Models and Measurements', Environment and Planning A, vol. 33 (2), pp. 219-136.

[27] Plummer, P. and Taylor, M. (2001b). 'Theories of Local Economic Growth: Part 2: Model Specification and Empirical Validation', Environment and Planning A, vol. 33 (3), pp. 385-398.

[28] Rogerson, R., Shimer, R., and Wright, R. (2005). 'Search-Theoretic Models of the Labor Market: A Survey', Journal of Economic Literature,vol. 43, pp. 959-988.

[29] Romer, P. (1990). 'Endogenous Technological Change', Journal of Political economy, vol. 98 (5), pp. S71-S102.

[30] Roy, A. (1951). 'Some Thoughts on the Distribution of Earnings', Oxford Economic Papers, vol. 3, pp. 135-146.

[31] Schumpeter, J. (1934). The Theory of Economic Development: Harvard University Press. 
[32] Stern, N. (1991). 'The Determinants of Growth', The Economic Journal, vol. 101 (404), pp. 122-133.

[33] Weel, B. (2006). 'Feature: IT Diffusion and Industry and Labour-market Dynamics', The Economic Journal, vol. 116, pp. F1-F9.

\section{Appendix}

Proof of result 2

(i) From (7), (8), (11) and (12) it is possible to obtain

$$
N_{1}^{\prime}-N_{1}=\int_{0}^{1} \int_{a_{2 R}}^{a_{2 R}^{\prime}} \frac{\beta^{2} \varphi(1-\varphi)}{(\beta \varphi+\delta)(\beta+\delta)} d a_{2} d a_{1}+\frac{\beta \varphi}{\beta+\delta}\left\{\begin{array}{c}
\int_{0}^{\hat{a}_{1}^{\prime}} \int_{a_{1 R}^{-1}}^{a_{1 R}^{-1^{\prime}}} 1 d a_{2} d a_{1} \\
+\int_{\hat{a}_{1}^{\prime}}^{\hat{a}_{1}} \int_{a_{1 R}^{-1}}^{1} 1 d a_{2} d a_{1}
\end{array}\right\}>0
$$

Given that $\hat{a}_{2}<\hat{a}_{2}^{\prime}$, it follows that:

$$
N_{2}^{\prime}-N_{2}=\frac{\beta(1-\varphi)}{\beta+\delta}\left(\frac{\hat{a}_{2}-\hat{a}_{2}^{\prime}}{2}\right)-\int_{0}^{1} \int_{a_{1 R}^{\prime}}^{a_{1 R}} \frac{\beta^{2} \varphi(1-\varphi)}{[\beta(1-\varphi)+\delta](\beta+\delta)} d a_{1} d a_{2}<0
$$

Adopting a similar procedure equations (9), (10), (13) and (14) yields:

$$
\begin{gathered}
Y_{1}^{\prime}-Y_{1}=\frac{\beta^{2} \varphi(1-\varphi) k^{\prime}}{(\beta \varphi+\delta)(\beta+\delta)} \int_{0}^{1} a_{1} a_{2 R}^{\prime} d a_{1}-\frac{\beta^{2} \varphi(1-\varphi) k}{(\beta \varphi+\delta)(\beta+\delta)} \int_{0}^{1} a_{1} a_{2 R} d a_{1} \\
+\frac{\beta \varphi}{\beta+\delta}\left\{\frac{k\left(\hat{a}_{1}\right)^{2}}{6}-\frac{k^{\prime}\left(\hat{a}_{1}^{\prime}\right)^{2}}{6}+\frac{\left(k^{\prime}-k\right)}{2}\right\}>0 \\
Y_{2}^{\prime}-Y_{2}=\frac{\beta(1-\varphi)}{\beta+\delta}\left[\frac{\left(\hat{a}_{2}\right)^{2}-\left(\hat{a}_{2}^{\prime}\right)^{2}}{6}\right]-\int_{0}^{1} \int_{a_{1 R}^{\prime}}^{a_{1 R}} \frac{\beta^{2} \varphi(1-\varphi) a_{2}}{[\beta(1-\varphi)+\delta](\beta+\delta)} d a_{1} d a_{2}<0
\end{gathered}
$$

where $N_{1}^{\prime}, Y_{1}^{\prime}\left(N_{2}^{\prime}, Y_{2}^{\prime}\right)$ denote the new steady state for, respectively employment and output in sector1 (2).

(ii) Adding A.2 to A.1, yields: 


$$
\begin{aligned}
Y_{1}^{\prime}-Y_{1}+Y_{2}^{\prime}-Y_{2}= & \frac{\beta^{3}(1-\varphi) \varphi}{3(\beta+\delta)}\left\{\begin{array}{c}
\frac{\varphi}{[\beta \varphi+r+\delta]}\left(k^{2}-k^{\prime 2}\right)\left[\frac{2 r+\delta+\beta \varphi}{2[\beta \varphi+\delta][\beta \varphi+r+\delta]}\right] \\
-\frac{1-\varphi}{[\beta(1-\varphi)+r+\delta]}\left(\frac{1}{k}-\frac{1}{k^{\prime}}\right)\left[\frac{2 r+\delta+\beta(1-\varphi)}{2[\beta(1-\varphi)+\delta][\beta(1-\varphi)+r+\delta]}\right]
\end{array}\right\} \\
& +\frac{\beta \varphi\left(k^{\prime}-k\right)}{2(\beta+\delta)}
\end{aligned}
$$

which is positive since $k^{\prime}-k>\frac{1}{k}-\frac{1}{k^{\prime}}$.

Proof of result 3

(i) From (11) comparing employment in Sector 1 on impact (i.e. $t=0$ ), relative to the trend, gives:

$$
N_{10}-\lim _{t \rightarrow \infty} N_{1 t}=-\int_{0}^{1} \int_{a_{2 R}}^{a_{2 R}^{\prime}} \frac{\beta^{2} \varphi(1-\varphi)}{(\beta \varphi+\delta)(\beta+\delta)} d a_{2} d a_{1}-\frac{\beta \varphi}{\beta+\delta}\left\{\begin{array}{c}
\int_{0}^{\hat{a}_{1}^{\prime}} \int_{a_{1 R}^{-1}}^{a_{1 R}^{-1^{\prime}}} 1 d a_{2} d a_{1} \\
+\int_{\hat{a}_{1}^{\prime}}^{\hat{a}_{1}} \int_{a_{1 R}^{-1}}^{1} 1 d a_{2} d a_{1}
\end{array}\right\}<0
$$

The absolute impact on employment in Sector 1 can be obtained by comparing (9) with $N_{10}$ :

$$
N_{10}-N_{1}=\frac{\beta \varphi}{\beta+\delta}\left\{\begin{array}{c}
\int_{0}^{1} a_{2 R}^{\prime} d a_{1}-\int_{0}^{1} a_{2 R} d a_{1} \\
+\int_{0}^{\hat{a}_{1}} a_{1 R}^{-1} d a_{1}-\int_{0}^{\hat{a}_{1}} a_{2 R}^{\prime} d a_{1} \\
+\int_{\hat{a}_{1}}^{1} 1 d a_{1}-\int_{\hat{a}_{1}}^{1} a_{2 R}^{\prime} d a_{1} \\
-\int_{0}^{\hat{a}_{1}} a_{1 R}^{-1} d a_{1}+\int_{0}^{\hat{a}_{1}} a_{2 R} d a_{1}-\int_{\hat{a}_{1}}^{1} 1 d a_{1}+\int_{\hat{a}_{1}}^{1} a_{2 R} d a_{1}
\end{array}\right\}=0
$$

(ii) Likewise, from (13) the change relative to the trend and the absolute change in Sector 1's output are given as follows:

$$
Y_{10}-\lim _{t \rightarrow \infty} Y_{1 t}=-\int_{0}^{1} \int_{a_{2 R}}^{a_{2 R}^{\prime}} \frac{\beta^{2} \varphi(1-\varphi) k^{\prime} a_{1}}{(\beta \varphi+\delta)(\beta+\delta)} d a_{2} d a_{1}-\frac{\beta \varphi}{\beta+\delta}\left\{\begin{array}{c}
\int_{0}^{\hat{a}_{1}^{\prime}} \int_{a_{1 R}^{-1}}^{a_{1 R}^{-1^{\prime}}} k^{\prime} a_{1} d a_{2} d a_{1} \\
+\int_{\hat{a}_{1}^{\prime}}^{\hat{a}_{1}} \int_{a_{1 R}^{-1}}^{1} k^{\prime} a_{1} d a_{2} d a_{1}
\end{array}\right\}<0
$$

Provided that $k^{\prime}>k$, then

$$
Y_{10}-Y_{1}=\int_{0}^{1} \int_{0}^{a_{2 R}} \frac{\left(k^{\prime}-k\right) \beta^{2} \varphi(1-\varphi) a_{1}}{(\beta \varphi+\delta)(\beta+\delta)} d a_{2} d a_{1}+\frac{\beta \varphi}{\beta+\delta}\left\{\begin{array}{c}
\int_{\hat{a}_{1}}^{1}\left(k^{\prime}-k\right) a_{1} d a_{1} \\
+\int_{0}^{\hat{a}_{1}} a_{1 R}^{-1}\left(k^{\prime}-k\right) a_{1} d a_{1}
\end{array}\right\}>0
$$


(iii) A process similar to (i) and (ii) allows from (12) and (14) to obtain the following results

$$
\begin{gathered}
N_{20}-\lim _{t \rightarrow \infty} N_{2 t}=\int_{0}^{1} \int_{a_{1 R}^{\prime}}^{a_{1 R}} \frac{\beta^{2} \varphi(1-\varphi)}{[\beta(1-\varphi)+\delta](\beta+\delta)} d a_{1} d a_{2}>0 \\
N_{20}-N_{2}=-(1-\varphi) \frac{\beta}{\beta+\delta}\left(\frac{\beta \varphi}{\beta \varphi+r+\delta}\right)\left(\frac{k^{\prime}-k}{2}\right)<0 \\
Y_{20}-\lim _{t \rightarrow \infty} Y_{2 t}=\int_{0}^{1} \int_{a_{1 R}^{\prime}}^{a_{1 R}} \frac{a_{2} \beta^{2} \varphi(1-\varphi)}{[\beta(1-\varphi)+\delta](\beta+\delta)} d a_{1} d a_{2}>0 \\
Y_{20}-Y_{2}=-\frac{(1-\varphi) \beta^{3} \varphi^{2}\left(k^{\prime 2}-k^{2}\right)}{6(\beta+\delta)(\beta \varphi+r+\delta)^{2}}<0
\end{gathered}
$$

Proof of result 4

As the time interval becomes infinitesimally small, from (11), (12), (13) and (14) we obtain,

$$
\begin{aligned}
N_{1 t}= & \int_{0}^{1} \int_{0}^{a_{2 R}} \frac{\beta \varphi}{\beta \varphi+\delta} d a_{2} d a_{1}+ \\
& \int_{0}^{1} \int_{a_{2 R}}^{a_{2 R}^{\prime}}\left\{e^{-\delta t} \frac{\beta \varphi}{\beta+\delta}+\left[1-e^{-\delta t}\right] \frac{\beta \varphi}{\beta \varphi+\delta}\right\} d a_{2} d a_{1}+ \\
& \varphi\left[\begin{array}{c}
\left.\int_{0}^{\hat{a}_{1}} \int_{a_{2 R}^{\prime}}^{a_{1 R}^{-1}} \xi d a_{2} d a_{1}+\int_{0}^{\hat{a}_{1}^{\prime}} \int_{a_{1 R}^{-1}}^{a_{1 R}^{-1}}\left[1-e^{-(\beta+\delta) t}\right] \xi d a_{2} d a_{1}+\right] \\
\int_{\hat{a}_{1}^{\prime}}^{\hat{a}_{1}} \int_{a_{1 R}^{-1}}^{1}\left[1-e^{-(\beta+\delta) t}\right] \xi d a_{2} d a_{1}+\int_{\hat{a}_{1}}^{1} \int_{a_{2 R}^{\prime}}^{1} \xi d a_{2} d a_{1}
\end{array}\right] \\
N_{2 t}= & \int_{0}^{1} \int_{0}^{a_{1 R}^{\prime}} \frac{\beta(1-\varphi)}{\beta(1-\varphi)+\delta} d a_{1} d a_{2}+ \\
& \int_{0}^{1} \int_{a_{1 R}^{\prime}}^{a_{1 R}}\left\{e^{-(\beta+\delta) t} \frac{\beta(1-\varphi)}{\beta(1-\varphi)+\delta}+\left(1-e^{-(\beta+\delta) t}\right) \frac{\beta(1-\varphi)}{\beta+\delta}\right\} d a_{1} d a_{2}+ \\
& (1-\varphi)\left[\int_{0}^{\hat{a}_{2}^{\prime}} \int_{a_{1 R}}^{a_{2 R}^{-1^{\prime}}} \xi d a_{1} d a_{2}+\int_{\hat{a}_{2}^{\prime}}^{1} \int_{a_{1 R}}^{1} \xi d a_{1} d a_{2}\right]
\end{aligned}
$$




$$
\begin{aligned}
& Y_{1 t}=\int_{0}^{1} \int_{0}^{a_{2 R}} k^{\prime} a_{1} \frac{\beta \varphi}{\beta \varphi+\delta} d a_{2} d a_{1}+ \\
& \int_{0}^{1} \int_{a_{2 R}}^{a_{2 R}} k^{\prime} a_{1}\left\{e^{-\delta t} \frac{\beta \varphi}{\beta+\delta}+\left[1-e^{-\delta t}\right] \frac{\beta \varphi}{\beta \varphi+\delta}\right\} d a_{2} d a_{1}+ \\
& \varphi\left[\begin{array}{c}
\int_{0}^{\hat{a}_{1}} \int_{a_{2 R}^{\prime}}^{a_{1 R}^{-1}} k^{\prime} a_{1} \xi d a_{2} d a_{1}+ \\
\int_{0}^{\hat{a}_{1}^{\prime}} \int_{a_{1 R}^{-1}}^{a_{1 R}^{-1^{\prime}}} k^{\prime} a_{1}\left[1-e^{-(\beta+\delta) t}\right] \xi d a_{2} d a_{1}+ \\
\int_{\hat{a}_{1}^{\prime}}^{\hat{a}_{1}} \int_{a_{1 R}^{-1}}^{1} k^{\prime} a_{1}\left[1-e^{-(\beta+\delta) t}\right] \xi d a_{2} d a_{1} \\
+\int_{\hat{a}_{1}}^{1} \int_{a_{2 R}^{\prime}}^{1} k^{\prime} a_{1} \xi d a_{2} d a_{1}
\end{array}\right] \\
& Y_{2 t}=\int_{0}^{1} \int_{0}^{a_{1 R}^{\prime}} a_{2} \frac{\beta(1-\varphi)}{\beta(1-\varphi)+\delta} d a_{1} d a_{2}+ \\
& \int_{0}^{1} \int_{a_{1 R}^{\prime}}^{a_{1 R}} a_{2}\left\{e^{-(\beta+\delta) t} \frac{\beta(1-\varphi)}{\beta(1-\varphi)+\delta}+\left(1-e^{-(\beta+\delta) t}\right) \frac{\beta(1-\varphi)}{\beta+\delta}\right\} d a_{1} d a_{2}+ \\
& (1-\varphi)\left[\int_{0}^{\hat{a}_{2}^{\prime}} \int_{a_{1 R}}^{a_{2 R}^{-1^{\prime}}} a_{2} \xi d a_{1} d a_{2}+\int_{\hat{a}_{2}^{\prime}}^{1} \int_{a_{1 R}}^{1} a_{2} \xi d a_{1} d a_{2}\right]
\end{aligned}
$$

Using A.3 and A.4, yields

$$
\begin{gathered}
\dot{N}_{1 t}=\int_{0}^{1} \int_{a_{2 R}}^{a_{2 R}^{\prime}} \delta e^{-\delta t} \frac{\beta^{2} \varphi(1-\varphi)}{(\beta \varphi+\delta)(\beta+\delta)} d a_{2} d a_{1}+\beta \varphi e^{-(\beta+\delta) t}\left\{\begin{array}{c}
\int_{0}^{\hat{a}_{1}^{\prime}} \int_{a_{1 R}^{-1}}^{a_{1 R}^{-1^{\prime}}} 1 d a_{2} d a_{1} \\
+\int_{\hat{a}_{1}^{\prime}}^{\hat{a}_{1}} \int_{a_{1 R}^{-1}}^{1} 1 d a_{2} d a_{1}
\end{array}\right\}>0 \\
\dot{N}_{2 t}=-\int_{0}^{1} \int_{a_{1 R}^{\prime}}^{a_{1 R}} \frac{\beta^{2} \varphi(1-\varphi) e^{-(\beta+\delta) t}}{[\beta(1-\varphi)+\delta]} d a_{1} d a_{2}<0
\end{gathered}
$$

Similarly, from A.5 and A.6 it can be shown that

$$
\begin{aligned}
& \dot{Y}_{1 t}>0 \\
& \dot{Y}_{2 t}<0
\end{aligned}
$$

